\title{
Chronic exposure to environmentally relevant levels of simvastatin disrupts zebrafish brain gene signalling involved in energy metabolism
}

Susana Barros ${ }^{\mathrm{a}, \mathrm{b}}$, Ana M. Coimbra ${ }^{\mathrm{b}}$, Nélson Alves ${ }^{\mathrm{a}}$, Marlene Pinheiro ${ }^{\mathrm{a}}$, José Benito Quintanac, Miguel M. Santos ${ }^{\mathrm{a}, \mathrm{d},{ }^{*},+}$, Teresa Neuparth ${ }^{\mathrm{a},{ }^{,},+}$

a - CIMAR/CIIMAR - Interdisciplinary Centre of Marine and Environmental Research, Endocrine Disruptors and Emerging Contaminants Group, University of Porto, Avenida General Norton de Matos, S/N, 4450-208 Matosinhos, Portugal

b - Centre for the Research and Technology of Agro-Environmental and Biological Sciences (CITAB), University of Trás-os-Montes and Alto Douro (UTAD), Quinta de Prados, 5000-801 Vila Real, Portugal

c - Department of Analytical Chemistry, Nutrition and Food Sciences, IAQBUS - Institute of Research on Chemical and Biological Analysis, Universidade de Santiago de Compostela, Constantino Candeira S/N, 15782 Santiago de Compostela, Spain d - FCUP - Department of Biology, Faculty of Sciences, University of Porto (U. Porto), Porto, Portugal

* Corresponding author at: CIMAR/CIIMAR-Interdisciplinary Centre of Marine and Environmental Research, Endocrine Disruptors and Emerging Contaminants Group, University of Porto, Avenida General Norton de Matos, S/N, 4450-208 Matosinhos, Portugal. E-mail addresses: tneuparth@ciimar.up.pt (T. Neuparth), santos@ciimar.up.pt (M. M. Santos).

+ Teresa Neuparth and Miguel M. Santos contributed equally to this study 


\title{
Chronic exposure to environmentally relevant levels of simvastatin disrupts zebrafish brain gene signalling involved in energy metabolism
}

\begin{abstract}
Simvastatin (SIM), a hypocholesterolaemic drug of the statins group, is among the most prescribed pharmaceuticals for the prevention of cardiovascular diseases. Several studies have shown that lipophilic statins, as SIM, are able to cross the blood-brain barrier and interfere with the energy metabolism of the central nervous system in humans and mammalian models. In fish and other aquatic organisms, the effects of SIM on the brain energy metabolism are unknown, particularly following exposure to low environmentally relevant concentrations. Therefore, the present study aimed at investigating the effects of SIM on gene signalling pathways involved in brain energy metabolism of adult zebrafish (Danio rerio) following a chronic exposure (90 days) to environmentally relevant SIM concentrations ranging from $8 \mathrm{ng} / \mathrm{L}$ to $1000 \mathrm{ng} / \mathrm{L}$. Real-Time PCR was used to determine the transcript levels of several genes involved in different pathways of the brain energy metabolism (glut1b, gapdh, acadm, acca, fasn, idh3a, cox4il, and cox5aa) and the findings here reported integrated well with the ecological and biochemical responses obtained in a parallel study. The results showed that SIM can modulate the transcription of key genes involved in the mitochondrial electron transport chain, in glucose transport and metabolism, in fatty acid synthesis and $\beta$-oxidation. Furthermore, SIM exposure led to a sex-dependent transcription profile for some of the studied genes. Overall, the present study shows, for the first time, that SIM can modulate gene regulation of key pathways involved in the energy metabolism in fish brain at environmentally relevant concentrations.
\end{abstract}

Keywords: Zebrafish; Simvastatin; Chronic exposure; Gene signalling; Brain metabolism; Low-level exposures

\section{Introduction}

Over the last decade, the detection level of pharmaceuticals in the aquatic environment has been increasing and several classes of pharmaceuticals are now detected at concentrations between ng/L to low $\mu \mathrm{g} / \mathrm{L}$ (Arnold et al., 2014; Azzouz and Ballesteros, 
2012; BIO Intelligence Service, 2013; Daughton, 2016; Fent, Weston and Caminada, 2006; Rodil et al., 2012). As bioactive chemicals, pharmaceuticals are designed to produce biological effects at rather low concentrations, and therefore potential effects on non-target aquatic organisms cannot be excluded (BIO Intelligence Service, 2013, Santos et al., 2018).

Simvastatin (SIM), a hypocholesterolaemic pharmaceutical of the statins class, is widely prescribed in developed countries to reduce cholesterol levels and prevent coronary heart diseases (Burg and Espenshade, 2011; Igel, Sudhop and VonBergman, 2001; Neuparth et al., 2014). From an ecotoxicological standpoint, and considering that SIM use has greatly increased during the past decades, its presence on aquatic bodies is a matter of serious concern (Pereira et al., 2015; Santos et al., 2016). In fact, relevant amounts of SIM are continuously reaching the surface waters due to the lack of efficient mechanisms to eliminate the statins from effluents of wastewater treatment plants (WWTPs) (Fent, Weston and Caminada, 2006; Lapworth et al., 2012, Tete et al., 2019). Furthermore, SIM has been detected worldwide in WWTPs effluents and influents at concentrations up to $1500 \mathrm{ng} / \mathrm{L}$ and $8 \mu \mathrm{g} / \mathrm{L}$, respectively (Kasprzyk-Hordern, Dinsdale and Guwy, 2009; Miao and Metcalfe, 2003; Ottmar, Colosi and Smith, 2012; Pereira et al., 2015; Pereira et al., 2016; Sousa, 2013; Verlicchi, Aukidy and Zambello, 2012). An estimation of 369.8 and $630 \mathrm{ng} / \mathrm{L}$ for environmental concentrations of SIM in Portuguese and Norwegian surface waters, respectively, has been previously reported by Grung et al. (2007) and Pereira et al. (2015).

Consequently, fish can be continually exposed to SIM, and statins in general, in their natural habitats and several studies have reported multiple detrimental effects of SIM in fish (Crespo and Solé, 2016; Cunha, Santos and Ferreira, 2016; Cunha et al., 2017; Thorpe et al., 2004). The effects described in zebrafish (Danio rerio) include morphological and physiological alterations in embryos, movement and heartbeat reduction, disruption of detoxification mechanisms, alteration in the transcription of genes related to the cholesterol biosynthesis pathway, as well as, genes encoding nuclear receptors implicated in lipid homeostasis (RXR) and development (RAR) (Al-Habsi, Massarsky and Moon, 2016; Barros et al., 2018; Campos et al., 2016; Cunha, Santos and Ferreira, 2016; Ribeiro et al., 2015). However, despite the diversity of studies regarding the adverse effects of statins in aquatic vertebrates, very few mechanistic studies are available regarding the effects of statins besides the cholesterol branch of the mevalonate 
(MVA) pathway. To the best of our knowledge the exception is the Eisa-Beygi et al. (2013) study reporting that statins perturb cerebral-vascular stability in zebrafish embryos due to the depletion of protein geranylgeranylation and the Gjini et al. (2011) study showing that statins affects vessel stability in zebrafish larvae through Tie-2 (member of the receptor tyrosine kinase family). Nevertheless, given the conservation status of the MVA pathway among vertebrates (Pertusa et al, 2007; Santos et al., 2016), it is expected that fish could display similar responses to those described in mammals.

In vertebrates, this class of pharmaceuticals is well known to inhibit the enzyme 3-hydroxy-3-methyl-glutaryl-CoA reductase (HMGCR) which is the rate limiting enzyme in the MVA pathway responsible for the biosynthesis of cholesterol (Al-Habsi, Massarsky and Moon, 2016; Blumenthal, 2000; Endo, Kuroda and Tsujita, 1976; Fent, Weston and Caminada, 2006; Sehayek, et al., 1994). Cholesterol aside, the MVA pathway is also involved in the synthesis of other important non sterol isoprenoids, such as coenzyme Q and geranylgeranyl pyrophosphate (GGPP), which play an essential role in cellular physiology (Figure 1) (Beltowski, Wojcicka and Jamroz-Wisniewska, 2009). The effects of statins in the kinetics of the enzymes involved in the MVA pathway have been thoroughly studied in mammalian models but, to the best of our knowledge, very few mechanistic studies have been performed in aquatic organisms. In humans and mammalian models, statins have been associated with pleiotropic effects, such as prevention of cardiovascular diseases, anticancer activity, immunomodulation and neuroprotection (Chen et al., 2016; Freed-Pastor et al., 2012; Schointuch et al., 2014). Nonetheless, statins have also been reported to induce several adverse effects (myopathy, cognitive dysfunction, diabetes, among others), which have been associated with either the depletion of coenzyme Q, protein prenylation and dolichol (final end products of the MVA pathway in the non-sterol branch) or with acetyl-CoA accumulation in the cells through mechanisms that are linked with alterations of the energy metabolism (Figure 1) (Betowski, Wojcicka and Jamroz-Wisniewska, 2009; du Souich, Roederer and Dufour, 2017; Greenwood, Steinman and Zamvil, 2006; Sirvent et al., 2012).

Following the considerations mentioned above, the present study was performed to investigate the effects of SIM in the regulation of molecular pathways involved in the energy metabolism of the model teleost fish zebrafish. This study is a component of a larger investigation that consisted on the assessment of the effects of environmentally relevant concentrations of SIM (8ng/L to 1000ng/L) in zebrafish following a chronic 
exposure of 90 days. Here we focus on the effects of SIM in the regulation of molecular pathways involved in the brain energy metabolism, while key ecological responses (survival, growth, reproduction and embryonic development), biochemical and molecular markers of lipid homeostasis in liver were reported in a previous publication - Barros et al. (2018).

Zebrafish was selected to conduct this experiment since it is one of the recommended test species for ecotoxicological studies (Segner, 2009) and due to its close phylogeny with mammalians, with highly conserved genes and protein functions (Fang and Miller, 2012). The brain was chosen for the present study, since it is the main organ responsible for regulating energy homeostasis in the body. Due to its high lipophilicity, SIM is able to cross the blood-brain barrier (Moghadasian, 1999), making the brain an interesting case study, since the effects of SIM in the central nervous system are still poorly understood. The main substrate for energy production in the brain is glucose that is transported through the blood-brain barrier by the glucose transporters (glut1b), which gene expression may be affected by cholesterol levels (Patching, 2017; Xiuli, Meiyu and Guanhua, 2005) (Figure 1 ). Once inside the cell, glucose participates in glycolysis and produces tryptophan, a process in which the gene encoding glyceraldehyde 3-phosphate dehydrogenase (gapdh) plays a major role (Ganapathy-Kanniappan, 2018; Seidler, 2013). After being transported to the mitochondrial matrix, tryptophan produces acetyl-CoA, which in cases of low amounts of glucose, may be obtained by fatty acid $\beta$-oxidation carried out by the medium-chain acyl-CoA dehydrogenase (acadm) (Eaton, Bartlett and Pourfarzam, 1996; Hashimoto, 1999). As fatty acids are too big to cross the blood-brain barrier, these molecules are synthesized in the cytosol of brain cells from the available acetyl-CoA through the action of Acetyl-CoA carboxylase alpha $(a c c \alpha)$ and fatty acid synthase (fasn) (Lyssimachou et al., 2015) (Figure 1). Mitochondrial acetyl-CoA will then feed the tricarboxylic acid cycle, in which the isocitrate dehydrogenase encoding gene (idh3a) is essential (Findlay et al., 2018; Sazanov and Jackson, 1994), and the resulting products are sent to the electron transport chain. The electron transport chain is the main ATP producer and several MVA pathway end products are able to influence this process, such as ubiquinones - CoQ (essential for the maintenance of the electron transport between complexes (Figure 1), as well as geranylgeranyl pyrophosphate (GGPP) and farnesyl pyrophosphate (FPP) that have been reported to affect the complex IV of the electron transport chain, where the genes cytochrome c oxidase subunits $4 \mathrm{i} 1$ 
(cox4i1) and 5aa (cox5aa) play major roles (Arnold, 2012; Fornuskova et al., 2010; Kadenbach et al., 2000). (Figure 1). Following the key role of the above mentioned genes, in this study we screened the effects of SIM on the expression pattern of the genes involved in the regulation of the brain energy metabolism.

\section{Material and Methods}

\subsection{Zebrafish maintenance}

Wild-type zebrafish, 50-days old, were obtained from Orniex, Portugal (purchased from a local supplier in Singapore). The organisms were acclimatized to laboratory conditions, during 15 days, in a $250 \mathrm{~L}$ aquarium filled with dechlorinated and filtered water with constant aeration. Fish were kept at $28 \pm 1^{\circ} \mathrm{C}$ with a photoperiod of $14: 10 \mathrm{~h}$ (light:dark) and fed, ad libitum, two times a day with a commercial fish diet - Tetramin (Tetra, Melle, Germany). The water parameters $\mathrm{pH}$, ammonia and nitrates were monitored twice a week.

\subsection{Chronic toxicity bioassay}

The assay was carried out at the Aquatic Animal Facilities of the Interdisciplinary Centre of Marine and Environmental Research (CIIMAR), Portugal. The experiment was ethical reviewed and approved by the CIIMAR animal welfare body (ORBEA, 2010/63/EU Directive) according to the European Directive 2010/63/EU concerning the use of animals for scientific research.

A broad description of the experimental conditions of the chronic toxicity test was presented in the first part of this study, which aimed at evaluating the effects of SIM in ecological relevant endpoints (morphometric endpoints, reproduction and embryonic development), biochemical (cholesterol and triglyceride levels in liver) and molecular markers (transcription of genes related to the cholesterol branch of the mevalonate pathway in the liver) (Barros et al., 2018). Briefly, the experiment consisted of five treatments with two replicates each: the control (0.0002\% acetone), and four increasing nominal concentrations of SIM (8, 40, 200, and $1000 \mathrm{ng} / \mathrm{L}$, prepared in $0.0002 \%$ acetone). SIM (CAS no. 79902-63-9; $\geq 97 \%$ HPLC) was obtained by Sigma Aldrich ${ }^{\circledR}$. The concentrations of SIM used in the present study were based on our previous research (Neuparth et al., 2014), which observed a severe impact on the reproduction of the 
amphipod Gammarus locusta, after an exposure to SIM at environmentally relevant concentrations (ng/L range).

Two hundred and fifty juvenile zebrafish (25 animals per $30 \mathrm{~L}$ bare-bottom aquaria - 0.83 fish/L, randomly distributed) were chronically exposed to SIM, for 90 days, using a flow-through system by means of a peristaltic pump (ISM 444, ISMATEC). Before entering in the system, the dechlorinated tap water was heated and charcoal filtered. Throughout the experiment, the water flow in each aquarium was maintained at $1.08 \mathrm{~L}$ per hour, whereas the SIM working solutions (8, 40, 200 and $1000 \mathrm{ng} / \mathrm{L}$ ) were administrated directly twice a day, at $0 \mathrm{~h}$ and $8 \mathrm{~h}$, with a volume equivalent to the water renewal. The concentration of SIM in the aquaria was analysed by liquid chromatography-tandem mass spectrometry (LC-MS/MS) once during the bioassay, at $\mathrm{T}_{0} \mathrm{~h}$ after the first SIM addition of the day and 8 hours later, before the second SIM addition of the day $\left(\mathrm{T}_{8} \mathrm{~h}\right)$. At $\mathrm{T}_{8} \mathrm{~h}$, the minimum and maximum decay of SIM was $27.9 \%$ and 57.3\% in the 8 and 1000 ng/L SIM treatments, respectively (see Barros et al. 2018). The water contaminated with simvastatin, before being discarded, was recirculated for several days in a container with an activated carbon filter and ultraviolet light.

During the experiment, zebrafish were maintained under a 14:10 (light:dark) photoperiod and the water parameters such as $\mathrm{pH}$, ammonia and nitrates were monitored twice a week (pH $7.5 \pm 0.2$; ammonia $0.08 \pm 0.04 \mathrm{mg} / \mathrm{L}$ and nitrites $0.01 \pm 0.01 \mathrm{mg} / \mathrm{L}$ of $)$ whereas the temperature was measured daily $\left(28 \pm 1^{\circ} \mathrm{C}\right)$. Zebrafish were fed twice a day with Tetramin (Tetra, Melle, Germany), supplemented with 48-h-old live brine shrimp (Artemia sp.). The amount of food provided was equal for all aquaria, being adjusted during the bioassay according to fish development and size. At maturity, the sex ratio in each treatment was determined by visual inspection and confirmed at the sampling time by stereomicroscope observation of gonads. The registered sex ratiowas between 0.85 and 1.50 with no statistical variation among treatments (chi square $=0.995)$.

\subsection{Sampling}

At the end of the bioassay, animals were euthanized with an overdose of tricane methanesulfonate (300 mg/L). Brains from both males and females ( $\mathrm{n}=8 / \mathrm{sex})$ from each treatment were individually sampled, preserved in RNALater and stored at $-80{ }^{\circ} \mathrm{C}$ until gene expression analysis. Liver was also sampled and used in the first part of the study (Barros et al., 2018). 


\subsection{Gene expression}

\subsubsection{RNA isolation and cDNA synthesis}

RNA of eight male and eight female brains, from each treatment, was individually extracted by Illustra RNAspin Mini RNA Isolation Kit (GE Healthcare), in accordance with the manufacturer's protocol in a final elution volume of $25 \mu \mathrm{L}$ RNase-free water. RNA quantification was accomplished on a Take3 Micro-Volume Plate Reader (Biotech Synergy HT) coupled with the Gen5 (version 2.0) software. RNA quality was verified by electrophoresis (1.5\% agarose gel) and through the absorbance ratio ( $\lambda 260 / \lambda 280 \mathrm{~nm})$. For cDNA synthesis, the iScript ${ }^{\mathrm{TM}}$ cDNA Synthesis Kit (Bio-Rad) was used with $0.4 \mu \mathrm{g}$ of total RNA extracted.

\subsubsection{Primer design}

Zebrafish mRNA sequences for the selected genes (glut1b, gapdh, acadm, acca, fasn, idh3a, cox4i1 and cox5aa) and the reference genes (rpl8 and efl $\alpha$ ) were obtained from NCBI's database (Table 1). Specific primers were designed for qRT-PCR using the Primer designing tool "Primer - BLAST” (NCBI) and Beacon Designer (Premier Biosoft International). To confirm primer specificity, a PCR was conducted in a Tgradient termocycler (Biometra) and the ensuing products were run in a $1.5 \%$ agarose gel electrophoresis. The resulting bands of the expected size for each gene were cut and purified with GelPure (NzyTech), following the manufacturers' protocol and sent for sequencing at GATC (Eurofins Genomics). The sequencing results were then analysed with VecScreen (NCBI) and Geneious R10 (Biomatters Ltd) in order to confirm the amplified sequence (Table 1).

\subsection{3. $q R T-P C R$}

Quantitative Reverse Transcription PCR (qRT-PCR) was used to evaluate the gene expression profile of selected genes involved in the regulation of the brain energy metabolism. For each treatment, the expression of the target genes was individually determined with the Mastercycler ${ }^{\circledR}$ ep realplex system (Eppendorf). Brain cDNA samples were amplified in 96-well optical plates, in duplicates, with $5 \mu \mathrm{L}$ of NZYSpeedy qPCR Green Master Mix (2x) (NZYTech), $0.4 \mu \mathrm{L}$ of each primer (forward and reverse) at $10 \mu \mathrm{M}, 2 \mu \mathrm{L}$ of cDNA at $100 \mathrm{ng}$ and $2.2 \mu \mathrm{L}$ of water for a final reaction volume of 10 
$\mu \mathrm{L}$. For each plate, a two-step qRT-PCR program was performed: an initial denaturation at $95{ }^{\circ} \mathrm{C}(2 \mathrm{~min})$, followed by 40 cycles of amplification with denaturation at $95{ }^{\circ} \mathrm{C}(5 \mathrm{~s})$ and combined annealing and extension between $58-62{ }^{\circ} \mathrm{C} \mathrm{(25} \mathrm{s)} \mathrm{(Table} \mathrm{1).} \mathrm{A} \mathrm{melting}$ curve (from $55^{\circ} \mathrm{C}$ to $95^{\circ} \mathrm{C}$ ) was generated at the end of each run to confirm the specificity of the assay. The PCR products were analysed by gel electrophoresis to confirm the presence of single bands with the expected sizes (between 111 and $250 \mathrm{bp}$, Table 1). The PCR efficiency for the reference and the target genes was determined by standard curves, using serial dilutions of cDNA of all samples' pools (0.064 to $200 \mathrm{ng}$ of cDNA). The reactions efficiency ranged from $90 \%$ to $102 \%$ (Table 1) and the CTs of all genes were within the range of the standard curves, assuring optimal DNA amplification. The reference genes, rpl8 and efl $\alpha$, were used to normalize the relative transcription change of target genes that was calculated using the $2^{-\Delta \Delta \mathrm{Ct}}$ analysis method proposed by Livak and Schmittgen (2001). The control expression levels of the females were normalized to 1 and data were then expressed as fold changes relative to female' control.

\subsection{Statistical analysis}

Data were first checked for normality (Kolmogorov-Smirnov test) and homogeneity of variances (Levene's test) and transformed when ANOVA assumptions were not fulfilled. Two-way analysis of variance (ANOVA) was then used, with SIM treatments and sex as independent variables. When ANOVA reached significance, the Fisher's least significant difference - LSD test - was used for multiple comparations, with SIM treatments and sexes being compared. The significant threshold was set as $\mathrm{p}<0.05$. A heat-map of the gene expression profile was created using Morpheus software (https://software.broadinstitute.org/morpheus).

\section{Results}

\subsection{Gene expression}

Following 90 days of SIM exposure, the two selected reference genes encoding ribosomal protein L8 (rpl8) and elongation factor 1 alpha (efl $\alpha)$ showed no variation between control and exposed groups, nor between males and females (data not shown).

In SIM exposed groups, the expression level of all tested genes involved in the brain energy metabolism was found to be altered in either males, females, or both, with 
the exceptions of fasn and idh3a (Figures 2 and 3). Regarding glut1b, the gene involved in the glucose transport and metabolism, it was altered in a sex specific manner, being significantly down-regulated (4.97 fold) in males exposed to $40 \mathrm{ng} / \mathrm{L}$ of SIM, and significantly up-regulated (2.73 fold) in females exposed to $200 \mathrm{ng} / \mathrm{L}$ of SIM. Significant differences were also observed in glut1b expression between males and females for 200 and $1000 \mathrm{ng} / \mathrm{L}$ SIM. The mRNA levels of gapdh, involved in the glycolysis, were significantly changed by SIM exposure in both sexes. Males presented a downregulation at the lowest and highest concentrations, 8 and $1000 \mathrm{ng} / \mathrm{L}$ of SIM (3.02 and 3.19 fold) respectively, while females had the mRNA levels decreased by 4.05 and 3.43 fold after exposure to 8 and $40 \mathrm{ng} / \mathrm{L}$ of SIM, respectively. Significantly differences were also detected for gapdh at $200 \mathrm{ng} / \mathrm{L}$ SIM when males and females were compared. The transcription levels of acadm, a regulator of the $\beta$-oxidation of fatty acids, responded significantly different in males and females. In fact, male acadm was significantly upregulated (2.93 fold) after exposure to $40 \mathrm{ng} / \mathrm{L}$ of SIM, while females presented a downregulation (2.35 fold) for the same concentration. The transcription levels of acca, involved in fatty acid synthesis, presented significant differences between males and females for 8 and $200 \mathrm{ng} / \mathrm{L}$ SIM exposure. Regarding the genes encoding proteins of the electron transport chain, cox4i1 and cox5aa, the first showed a contrasting pattern between sexes after SIM exposure, similarly to acadm and glut1b. In fact, the cox4i1 expression profile exhibited a similar dose-response curve to glut1b. Male cox4i1 expression was significantly down-regulated by 2.65 and 2.44 fold after 40 and $200 \mathrm{ng} / \mathrm{L}$ of SIM exposure, respectively, while females presented an up-regulation by 2.57 fold after being exposed to $1000 \mathrm{ng} / \mathrm{L}$ of SIM. Moreover, cox4i1 presented significant differences between males and females for control and 40, 200, 1000 ng/L SIM. Lastly, mRNA levels of cox5aa were significantly down-regulated by 2.42 fold in females exposed to $40 \mathrm{ng} / \mathrm{L}$ of SIM. In males, the transcription of this gene did not show significant differences. However, similarly to females, a decrease of cox5aa was observed for $40 \mathrm{ng} / \mathrm{L}$ SIM exposure, however not being statistically significant $(\mathrm{p}=0.08)$. The majority of the gene expression profiles analysed in this study exhibited non-monotonic dose-response curves (NMDRC), either U or inverted U-shaped curves (Figure 2). 


\section{Discussion}

Several studies in mammalian models, including humans, suggest that the inhibition of the MVA pathway by statins induces a set of detrimental effects on the brain (Cibickova et al., 2008; Kannan et al., 2010; Lindberg et al., 2005; Schulz et al., 2004; Smolders et al., 2010; Thelen et al., 2006; Xiang and Reeves, 2009). In fact, it has been suggested that the effects of statins on the brain energy metabolism might be similar to the observed effects on skeletal muscle as both, muscle and brain, are post-mitotic tissues with high mitochondrial vulnerability and metabolic demand (Golomb and Evans, 2008). Although several energy regulatory mechanisms are conserved between fish and mammals (Lyssimachou et al., 2015; Soengas and Aldegunde, 2002), to the best of our knowledge, no studies are available on the interaction of statins with energy homeostasis in fish brain.

Apart from the growing body of evidence suggesting that the imbalance of cholesterol homeostasis plays an important role on several diseases of the central nervous system (Backes and Howard, 2003; Baytan et al., 2008; Kirsch, Eckert and Mueller, 2003; Marz, Otten and Miserez, 2007; Schulz et al., 2004; Vance, 2012), the reduction of MVA pathway end-products in the non-sterol branch, such as coenzyme Q (CoQ), farnesyl pyrophosphate (FPP) and geranylgeranyl-pyrophosphate (GGPP) have been suggested to be related with an impairment on the brain energy metabolism due to these end-products relation with the mitochondrial electron transport chain (Figure 1) (Mans, McMahon and Li, 2012; Oks et al., 2018). In the mitochondria, CoQ is responsible for electron transport during the oxidative phosphorylation, assuring ATP production in all cell types including neurons (Figure 1) (Littarru and Langsjoen, 2007). Additionally, a large number of molecules use FPP and GGPP as lipid moieties and its depletion, due to MVA inhibition by statins, affects a large variety of essential intracellular signalling pathways and functions, including the respiratory chain activity, particularly the complex IV (Figure 1) (Arenas et al., 2003; Mans, McMahon and Li, 2012; Ramachandran and Wierzbicki, 2017). In the present study, exposure to the intermediate concentrations of SIM (40 ng/L and/or $200 \mathrm{ng} / \mathrm{L}$ ) induced significant alterations in the transcript levels of zebrafish brain cox4i1 and cox5aa (Figure 2). These genes have an important function in the complex IV (COX enzymatic complex) of the electron transport chain, (Figure 1) which is responsible for the maintenance of a proton gradient in the mitochondrial membrane and for the continuous electron flow via oxidative phosphorylation (Rousseau and Han, 2002). 
Previous studies in humans have reported a decrease of COX activity on the skeletal muscle of patients treated with statins, which was associated with a depletion of FPP in the MVA pathway (Arenas et al., 2003; Duncan et al., 2009; Mans, McMahon and Li, 2012). These studies disclosed that statins treatment leads to an impairment of the electron transport chain, limiting aerobic cellular respiration. Consequently, the cellular metabolism may shift from aerobic to anaerobic, which produces much lower amounts of ATP (De Vivo and DiMauro, 1990). Although the impairment of the electron transport chain affects mainly the muscle function, the brain is also highly vulnerable to mitochondrial disruption (De Vivo and DiMauro, 1990). Similar to the studies in humans mentioned above, our results reported a downregulation of cox4i1 and cox5aa which suggest that SIM is able to disrupt the electron transport chain in zebrafish brain. Since the brain is highly energy dependent, these alterations could cause meaningful adverse effects in fish populations, since brain is the regulatory centre of the whole body and small changes in the energy metabolism are expected to affect a large number of biological processes.

As in mammals, fish brain relies mostly on the glucose metabolism for the production of acetyl-CoA, essential for the tricarboxylic acid cycle. Nowis et al. (2014) reported that in cultured human muscle cells SIM, as well as other statins, were able to alter gene transcription of glut1b limiting the glucose transport to the brain. Our results showed that the transcription of glut1b was altered at the intermediate SIM concentrations, $40 \mathrm{ng} / \mathrm{L}$ and /or $200 \mathrm{ng} / \mathrm{L}$, (a downregulation in males and an upregulation in females) which suggests that glucose uptake may be altered in the brain cells. These finding is supported by the observed changes in gapdh mRNA levels. gapdh is known to be a multifunctional protein, involved in several biological processes, essential for the glucose metabolism by its implication in the glycolysis and glycogenesis (Figure 1) (Kadmiri et al., 2014; Zala et al., 2013). When glucose is reduced, brain cells also rely on the fatty acid $\beta$-oxidation to obtain energy through the acetyl-CoA that participates in the TCA cycle (Lyssimachou et al., 2015; Soengas and Aldegunde, 2002). (Figure 1). Our results revealed that acadm, involved in the fatty acid $\beta$-oxidation, showed altered transcription levels, indicating a potential modulation of the glucose metabolism.

This study also revealed that the effects of SIM in the transcription of the genes glut1b, acadm and cox4i1 are sex dependent (Figures 2 - 3). Interestingly, the first part of this investigation (Barros et al., 2018) also indicated sex-dependent differences for the 
levels of cholesterol and triglycerides in zebrafish liver, which suggests that males and females have different lipid demands. Females tend to have a higher lipid content as an energy reserve in comparison to males, since female reproduction is a process demanding higher energy consumption (Vergauwen et al., 2010). The gene expression pattern here observed suggests different responses in both sexes which could have important implications of wild fish populations. For instance, the expression pattern of glut1b, cox4i1 and cox5aa, at intermediate SIM concentrations, indicates that male zebrafish are potentially compensating the low levels of energy associated with the downregulation of glut1b, cox4i1 and cox5aa by increasing fatty acid $\beta$-oxidation (upregulation of acadm). On the other hand, at the highest SIM concentration tested, females seem to increase brain energy by rising the glucose transportation into the brain through the blood-brain-barrier (upregulation of glut1b) and intensifying the production of ATP (upregulation of cox4i1). It is also possible that throughout the chronic exposure to SIM, zebrafish alternate between glucose transportation into the brain and fatty acid $\beta$-oxidation in order to maintain the energy balance in the central nervous system, which could explain the expression profile here presented. However, caution must be taken in the interpretation of these results given that only gene expression is provided and no protein activity was studied. Moreover, it is possible that the low SIM concentrations used in the present study cause fluctuations of the transcription of genes related with the brain energy metabolism in a time dependent manner, which highlights the importance of using multiple timepoints in gene expression studies with statins. This is an issue that should be explored in future research.

It is worth noting that SIM induced non-monotonic dose-response curves (NMDRCs) in $U$ and inverted U-shaped forms in many of the studied genes. This nonmonotonicity indicates that the lower SIM concentrations were able to induce more alterations in the transcript levels of the analysed genes. In fact, this kind of response has been increasingly detected in studies assessing the long-term effects of compounds, generally endocrine disrupting chemicals, at very low concentrations (Vandenberg et al., 2012). However, the mechanisms behind SIM non-monotonicity are poorly understood and should be further studied not only in fish, but also in other taxa. Again, the first part of this investigation (Barros et al., 2018) has also reported the occurrence of this nonmonotonic behaviour for several zebrafish responses in liver. In fact, Barros et al. (2018) showed that the exposition of zebrafish to the intermediate concentrations of SIM (8, 40 
and/or $200 \mathrm{ng} / \mathrm{L}$ ), presented a down-regulation of genes involved in the cholesterol branch of the MVA pathway, in parallel with significant alterations in triglycerides and cholesterol levels in the liver, as well as in zebrafish embryogenesis, while at the highest SIM concentration tested (1000 ng/L) the responses were similar to the control conditions.

In summary, the findings of the present study indicate that chronic exposure to environmentally relevant concentrations of SIM had significant impacts in the transcription levels of key genes involved in the brain energy metabolism of adult zebrafish, i.e, mitochondrial electron transport chain, glucose transport / metabolism and fatty acid synthesis and $\beta$-oxidation. This is of high concern given that the brain is particularly sensitive to alterations in the energy supply and thus adverse outcomes might occur since the brain is the main regulatory centre for the whole organism. The results here presented integrate well with the first part of this investigation (Barros et al., 2018) where the same SIM concentrations induced significant alterations on cholesterol and triglycerides levels in zebrafish liver, concomitantly with important impacts on key ecologically relevant endpoints (weight and embryonic development). All these findings

might have implications for wild fish populations, given that the effects reported have been observed at environmentally relevant concentrations. Considering the scarcity of knowledge regarding the effects of SIM in fish, the environmental relevance of the current findings requires future research that focus in additional characterization of the impacted signaling pathways and relate the MoA with adversity.

\section{Acknowledgements}

This study was developed under the project Nor-Water - Poluentes emergentes nas águas da Galiza-Norte de Portugal: novas ferramentas para gestão de risco (Reference: 0725_NOR_WATER_1_P), financed by "Programa de Cooperação Interreg Portugal/Espanha, (POCTEP) 2014-2020. The study was also supported by the National Funds through Portuguese Foundation for Science and Technology (FCT) under the projects UID/Multi/04423/2019 and UID/AGR/04033/2013. S. Barros was supported by the doctoral fellowship PD/BD/143090/2018 from FCT. J.B. Quintana acknowledges the financial support of Spanish "Agencia Estatal de Investigación" (ref. CTM2017-84763C3-R-2) and Xunta de Galicia (ref. ED431C2017/36), both co-funded by FEDER/ERDF. 


\section{Compliance with ethical standards}

Conflict of interest

The authors declare that they have no conflict of interest.

\section{References}

Al-Habsi, A. A., A. Massarsky and T. W. Moon. 2016. Exposure to gemfibrozil and atorvastatin affects cholesterol metabolism and steroid production in zebrafish (Danio rerio). Comparative Biochemistry and Physiology Part - B: Biochemistry and Molecular Biology, 199, 87-96. https://doi.org/10.1016/j.cbpb.2015.11.009

Arenas, J., M. A. Fernández-Moreno, J. A. Molina, V. Fernández, P. Del Hoyo, Y. Campos, P. Calvo, M. A. Martín, A. García, T. Moreno et al. 2003. Myoglobinuria and COX deficiency in a patient taking cerivastatin and gemfibrozil. Neurology, 60, 124-126. https://doi.org/10.1212/01.WNL.0000042050.85041.FB

Arnold, K. E., A. R. Brown, G. T. Ankley and J. P. Sumpter. 2014. Medicating the environment: assessing risks of pharmaceuticals to wildlife and ecosystems. Philosophical Transactions of the Royal Society of London. Series B, Biological Sciences, 369, 20130569-. https://doi.org/10.1098/rstb.2013.0569

Arnold, S. 2012. Cytochrome c Oxidase and Its Role in Neurodegeneration and Neuroprotection. In Mitochondrial Oxidative Phosphorylation (pp. 305-339). Springer, New York, NY. https://doi.org/10.1007/978-1-4614-3573-0_13

Azzouz, A., and E. Ballesteros. 2012. Combined microwave-assisted extraction and continuous solid-phase extraction prior to gas chromatography-mass spectrometry determination of pharmaceuticals, personal care products and hormones in soils, sediments and sludge. Science of the Total Environment, 419, 208-215. https://doi.org/10.1016/j.scitotenv.2011.12.058

Backes, J. M. and P. A. Howard. 2003. Association of HMG-CoA reductase inhibitors with neuropathy. Annals of Pharmacotherapy, 37, 274-278. https://doi.org/10.1177/106002800303700220

Barros, S., R. Montes, J. B. Quintana, R. Rodil, A. André, A. Capitão, J. Soares, M. M. Santos and T. Neuparth. 2018. Chronic environmentally relevant levels of 
simvastatin disrupt embryonic development, biochemical and molecular responses in zebrafish (Danio rerio). Aquatic Toxicology, 201, 47-57. https://doi.org/10.1016/j.aquatox.2018.05.014

Baytan, S. H., M. Alkanat, M. Okuyan, M. Ekinci, E. Gedikli, M. Ozeren and A. Akgun. 2008. Simvastatin Impairs Spatial Memory in Rats at a Specific Dose Level. The Tohoku Journal of Experimental Medicine, 214, 341-349. https://doi.org/10.1620/tjem.214.341

Beltowski, J., G.Wójcicka and A. Jamroz-Wiśniewska. 2009. Adverse Effects of Statins - Mechanisms and Consequences. Current Drug Safety, 4, 209-228. https://doi.org/10.2174/157488609789006949

BIO Intelligence Service. 2013. Study on the environmental risks of medicinal products. Final Report prepared for Executive Agency for Health and Consumers.

Blumenthal, R. S. 2000. Statins: Effective antiatherosclerotic therapy. American Heart Journal, 139, 577-583. https://doi.org/10.1016/S0002-8703(00)90033-4

Burg, J. S. and P. J. Espenshade. 2011. Regulation of HMG-CoA reductase in mammals and yeast. Progress in Lipid Research, 50, 403-410. https://doi.org/10.1016/j.plipres.2011.07.002

Campos, L. M., E. A. Rios, L. Guapyassu, V. Midlej, G. C. Atella, S. Herculano-houzel, M. Benchimol, C. Mermelstein, M. L. Costa. 2016. Alterations in zebrafish development induced by simvastatin: Comprehensive morphological and physiological study , focusing on muscle, Experimental Biology and Medicine, 241, 1950-1960. https://doi.org/10.1177/1535370216659944

Chen, T., B. Zhang, G. Li, L. Chen and L. Chen. 2016. Simvastatin enhances NMDA receptor GluN2B expression and phosphorylation of GluN2B and GluN2A through increased histone acetylation and Src signaling in hippocampal CA1 neurons. Neuropharmacology, 107, 411-421. https://doi.org/10.1016/j.neuropharm.2016.03.028

Cibickova, L., R. Hyspler, A. Ticha, N. Cibicek, V. Palicka, E. Cermakova and Z. Zadak. 2008. Cholesterol synthesis in central nervous system of rat is affected by simvastatin as well as by atorvastatin. Pharmazie, 63, 819-822 https://doi.org/10.1691/ph.2008.8539

Crespo, M. and M. Solé. 2016. The use of juvenile Solea solea as sentinel in the marine 
platform of the Ebre Delta: in vitro interaction of emerging contaminants with the liver detoxification system. Environmental Science and Pollution Research, 23, 19229-19236. https://doi.org/10.1007/s11356-016-7146-7

Cunha, V., M. M. Santos and M. Ferreira. 2016. Simvastatin effects on detoxification mechanisms in Danio rerio embryos. Environmental Science and Pollution Research, 23, 10615-10629. https://doi.org/10.1007/s11356-016-6547-y

Cunha, V., M. M. Santos, P. Moradas-Ferreira, L. F. C. Castro and M. Ferreira. 2017. Simvastatin modulates gene expression of key receptors in zebrafish embryos. Journal of Toxicology and Environmental Health, Part A, 80, 465-476. https://doi.org/10.1080/15287394.2017.1335258

Daughton, C. G. 2016. Pharmaceuticals and the Environment (PiE): Evolution and impact of the published literature revealed by bibliometric analysis. Science of the Total Environment, 562, 391-426. https://doi.org/10.1016/j.scitotenv.2016.03.109

De Vivo, D. C. and S. DiMauro. 1990. Mitochondrial Defects of Brain and Muscle. Neonatology, 58, 54-69. https://doi.org/https://doi.org/10.1159/000243300

du Souich, P., G. Roederer and R. Dufour. 2017. Myotoxicity of statins: Mechanism of action. Pharmacology \& Therapeutics, 175, 1-16. https://doi.org/10.1016/J.PHARMTHERA.2017.02.029

Duncan, A. J., I. P. Hargreaves, M. S. Damian, J. M. Land and S. J. R. Heales. 2009. Decreased ubiquinone availability and impaired mitochondrial cytochrome oxidase activity associated with statin treatment. Toxicology Mechanisms and Methods, 19, 44-50. https://doi.org/10.1080/15376510802305047

Eaton, S., K. Bartlett and M. Pourfarzam. 1996. Mammalian mitochondrial betaoxidation. The Biochemical Journal, 320, 345-357. https://doi.org/10.1042/bj3200345

Eisa-Beygi, S., G. Hatch, S. Noble, M. Ekker, W. Thomas and T.W. Moon. 2013. The 3-hydroxy-3-methylglutaryl-CoA reductase (HMGCR) pathway regulates developmental cerebral-vascular stability via prenylation-dependent signalling pathway. Developmental Biology, 373, 258-266. https://doi.org/10.1016/j.ydbio.2012.11.024

Endo, A., M. Kuroda and Y. Tsujita. 1976. ML-236A, ML-236B, and ML-236C, new inhibitors of cholesterogenesis produced by Penicillium citrinium. The Journal of Antibiotics, 29, 1346-1348. http://dx.doi.org/10.7164/antibiotics.29.1346 
Fang, L. and Y. I. Miller. 2012. Emerging applications for zebrafish as a model organism to study oxidative mechanisms and their roles in inflammation and vascular accumulation of oxidized lipids. Free Radical Biology and Medicine, 53, 14111420. https://doi.org/10.1016/j.freeradbiomed.2012.08.004

Fent, K., A.Weston and D. Caminada. 2006. Ecotoxicology of human pharmaceuticals. Aquatic Toxicology, 76, 122-159.

https://doi.org/10.1016/j.aquatox.2005.09.009

Findlay, A. S., R. N. Carter, B. Starbuck, L. McKie, K. Nováková, P. S. Budd, M. A. Keighren, J. A. Marsh, S. H. Cross, M. M. Simon et al. 2018. Mouse Idh3a mutations cause retinal degeneration and reduced mitochondrial function. Disease Models \& Mechanisms, 11, dmm.036426. https://doi.org/10.1242/dmm.036426

Fornuskova, D., L. Stiburek, L. Wenchich, K. Vinsova, H. Hansikova and J. Zeman. 2010. Novel insights into the assembly and function of human nuclear-encoded cytochrome c oxidase subunits 4, 5a, 6a, 7a and 7b. The Biochemical Journal, 428, 363-374. https://doi.org/10.1042/BJ20091714

Freed-Pastor, W.A., H. Mizuno, X. Zhao, A. Langerød, S.H. Moon, R. RodriguezBarrueco, A. Barsotti, A. Chicas, W. Li, A. Polotskaia et al. 2012. Mutant p53 Disrupts Mammary Tissue Architecture via the Mevalonate Pathway. Cell, 148, 244-258. https://doi.org/10.1016/j.cell.2011.12.017

Ganapathy-Kanniappan, S. 2018. Evolution of GAPDH as a druggable target of tumor glycolysis? Expert Opinion on Therapeutic Targets, 22, 295-298. https://doi.org/10.1080/14728222.2018.1449834

Gjini, E., L.H. Hekking, A. Küchler, P. Saharinen, E. Wienholds, J.A. Post, K. Alitalo and S. Stefan Schulte-Merker. 2011. Zebrafish Tie-2 shares a redundant role with Tie-1 in heart development and regulates vessel integrity. Disease Models \& Mechanisms 4: 57-66. https://doi: 10.1242/dmm.005033

Golomb, B.A. and M.A. Evans. 2008. Statin Adverse Effects: A Review of the Literature and Evidence for a Mitochondrial Mechanism. American Journal of Cardiovascular Drugs, 8, 373-418. https://doi.org/10.2165/0129784-200808060-00004

Greenwood, J., L. Steinman and S. S. Zamvil. 2006. Statin therapy and autoimmune disease: from protein prenylation to immunomodulation. Nature Reviews Immunology, 6, 358-370. https://doi.org/10.1038/nri1839

Grung, M., M.S. Heimstad, M. Moe, M. Schlabach, A. Svenson, K. Thomas and A. 
Woldegiorgis. 2007. Human and Veterinary Pharmaceuticals, Narcotics, andPersonal Care Products in the Environment. SFT Report (Oslo), TA-2325/2007, 98 pp.

Hashimoto, T. 1999. Peroxisomal $\beta$-Oxidation Enzymes. Neurochemical Research, 24, 551-563. https://doi.org/10.1023/A:1022540030918

Igel, M., T. Sudhop and K. VonBergmann. 2001. Metabolism and drug interactions of 3-hydroxy-3-methylglutaryl coenzyme A-reductase inhibitors (statins). European Journal of Clinical Pharmacology, 57, 357-364.

https://doi.org/10.1007/s002280100329

Kadenbach, B., M. Hüttemann, S. Arnold, I. Lee and E. Bender. 2000. Mitochondrial energy metabolism is regulated via nuclear-coded subunits of cytochrome c oxidase. Free Radical Biology and Medicine, 29, 211-221. https://doi.org/10.1016/S0891-5849(00)00305-1

Kadmiri, N. El, I. Slassi, B. El Moutawakil, S. Nadifi, A. Tadevosyan, A. Hachem and A. Soukri. 2014. Glyceraldehyde-3-phosphate dehydrogenase ( GAPDH ) and Alzheimer , s disease. Pathologie Biologie, 62, 8-11. https://doi.org/10.1016/j.patbio.2014.08.002

Kain, V., B. Kapadia, P. Misra and U. Saxena. 2015. Simvastatin may induce insulin resistance through a novel fatty acid mediated cholesterol independent mechanism. Scientific Reports, 5, 1-9. https://doi.org/10.1038/srep13823

Kannan, M., J.R. Steinert, I.D. Forsythe, A.G. Smith and T. Chernova. 2010. Mevastatin accelerates loss of synaptic proteins and neurite degeneration in aging cortical neurons in a heme-independent manner. Neurobiology of Aging, 31, 1543-1553. https://doi.org/10.1016/j.neurobiolaging.2008.09.004

Kasprzyk-Hordern, B., R.M. Dinsdale and A.J. Guwy. 2009. The removal of pharmaceuticals, personal care products, endocrine disruptors and illicit drugs during wastewater treatment and its impact on the quality of receiving waters. Water Research, 43, 363-380. https://doi.org/10.1016/j.watres.2008.10.047

Kirsch, C., G.P. Eckert and W.E. Mueller. 2003. Statin effects on cholesterol microdomains in brain plasma membranes. Biochemical Pharmacology, 65, 843-856. https://doi.org/10.1016/S0006-2952(02)01654-4

Koch, H. and Y.G. Weber. 2018. The glucose transporter type 1 ( Glut1 ) syndromes. Epilepsy \& Behavior, 91, 90-93. https://doi.org/10.1016/j.yebeh.2018.06.010 
Lapworth, D.J., N. Baran, M.E. Stuart and R.S. Ward. 2012. Emerging organic contaminants in groundwater: A review of sources, fate and occurrence. Environmental Pollution, 163, 287-303. https://doi.org/10.1016/j.envpol.2011.12.034

Lindberg, C., M. Crisby, B. Winblad and M. Schultzberg. 2005. Effects of statins on microglia. Journal of Neuroscience Research, 82, 10-19. https://doi.org/10.1002/jnr.20615

Littarru, G. P. and P. Langsjoen. 2007. Coenzyme Q10 and statins: Biochemical and clinical implications. Mitochondrion, 7, 168-174. https://doi.org/10.1016/j.mito.2007.03.002

Livak, K. J. and T.D. Schmittgen. 2001. Analysis of relative gene expression data using real-time quantitative PCR and the 2(- $\Delta \Delta \mathrm{CT})$ Method. Methods (San Diego, Calif.), 25, 402-408. https://doi.org/10.1006/meth.2001.1262

Lyssimachou, A., J.G. Santos, A. André, J. Soares, D. Lima, L. Guimarães, C.M.R. Almeida, C. Teixeira, L.F.C. Castro and M.M. Santos. 2015. The Mammalian “ Obesogen " Tributyltin Targets Hepatic Triglyceride Accumulation and the Transcriptional Regulation of Lipid Metabolism in the Liver and Brain of Zebrafish. PloS One, 10, 1-22. https://doi.org/10.1371/journal.pone.0143911

Mans, R. A., L. L. McMahon and L. Li. 2012. Simvastatin-mediated enhancement of long-term potentiation is driven by farnesyl-pyrophosphate depletion and inhibition of farnesylation. $\quad$ Neuroscience, 202, 1-9. https://doi.org/10.1016/J.NEUROSCIENCE.2011.12.007

Miao, X.S. and C.D. Metcalfe. 2003. Determination of cholesterol-lowering statin drugs in aqueous samples using liquid chromatography-electrospray ionization tandem mass spectrometry. Journal of Chromatography A, 998, 133-141. https://doi.org/10.1016/S0021-9673(03)00645-9

Moghadasian, M.H. 1999. Clinical pharmacology of 3-hydroxy-3-methylglutaryl coenzyme A reductase inhibitors. Life Sciences, 65, 1329-1337. http://dx.doi.org/10.1016/S0024-3205\%2899\%2900199-X

Neuparth, T., C. Martins, B. Carmen, M.H. Costa, I. Martins, P.M. Costa and M.M. Santos. 2014. Hypocholesterolaemic pharmaceutical simvastatin disrupts reproduction and population growth of the amphipod Gammarus locusta at the ng/L 
$\begin{array}{llll}\text { range. } & \text { Aquatic } & \text { Toxicology, } & \text { 337-347. }\end{array}$

https://doi.org/10.1016/j.aquatox.2014.07.009

Nicolás Vázquez, I., J.R. Rodríguez-Núñez, V. Peña-Caballero, R.M. Ruvalcaba and J.M. Aceves-Hernandez. 2017. Theoretical and experimental study of fenofibrate and simvastatin. Journal of Molecular Structure, 1149, 683-693. https://doi.org/10.1016/j.molstruc.2017.08.044

Nowis, D., A. Malenda, K. Furs, B. Oleszczak, R. Sadowski, J. Chlebowska, M. Firczuk, J.M. Bujnicki, A.D. Staruch, R. Zagozdzon et al. 2014. Statins impair glucose uptake in human cells. BMJ Open Diabetes Research \& Care, 2, 1-10. https://doi.org/10.1136/bmjdrc-2014-000017

Oks, O., S. Lewin, I.L. Goncalves and A. Sapir. 2018. The UPRmt Protects Caenorhabditis elegans from Mitochondrial Dysfunction by Upregulating Specific Enzymes of the Mevalonate Pathway. Genetics, 209, 457-473. https://doi.org/10.1534/genetics.118.300863

Ottmar, K.J., L.M. Colosi, and J.A. Smith. 2012. Fate and transport of atorvastatin and simvastatin drugs during conventional wastewater treatment. Chemosphere, 88, 1184-1189. https://doi.org/10.1016/j.chemosphere.2012.03.066

Patching, S.G. 2017. Glucose Transporters at the Blood-Brain Barrier: Function, Regulation and Gateways for Drug Delivery. Molecular Neurobiology, 54, 10461077. https://doi.org/10.1007/s12035-015-9672-6

Pereira, A.M.P.T., L.J.G. Silva, C.M. Lino, L.M. Meisel and A. Pena. 2016. Assessing environmental risk of pharmaceuticals in Portugal: An approach for the selection of the Portuguese monitoring stations in line with Directive 2013/39/EU. Chemosphere, 144, 2507-2515. https://doi.org/10.1016/j.chemosphere.2015.10.100 Pereira, A.M.P.T., L.J.G. Silva, L.M. Meisel, C.M. Lino and A. Pena. 2015. Environmental impact of pharmaceuticals from Portuguese wastewaters: geographical and seasonal occurrence, removal and risk assessment. Environmental Research, 136, 108-119. https://doi.org/10.1016/j.envres.2014.09.041

Pertusa, M., S. García-Matas, E. Rodríguez-Farré, C. Sanfeliu and R. Cristòfol. 2007. Astrocytes aged in vitro show a decreased neuroprotective capacity. Journal of Neurochemistry, 101, 794-805. https://doi.org/10.1111/J.1471-4159.2006.04369.X Ramachandran, R. and A. Wierzbicki. 2017. Statins, Muscle Disease and Mitochondria. 
Journal of Clinical Medicine, 6, 75. https://doi.org/10.3390/jcm6080075

Ribeiro, S., T. Torres, R. Martins and M.M. Santos. 2015. Toxicity screening of diclofenac, propranolol, sertraline and simvastatin using Danio rerio and Paracentrotus lividus embryo bioassays. Ecotoxicology and Environmental Safety, 114, 67-74. https://doi.org/10.1016/j.ecoenv.2015.01.008

Rodil, R., J.B. Quintana, E. Concha-Graña, P. López-Mahía, S. Muniategui-Lorenzo and D. Prada-Rodríguez. 2012. Emerging pollutants in sewage, surface and drinking water in Galicia (NW Spain). Chemosphere, 10401049.https://doi.org/10.1016/j.chemosphere.2011.11.053

Rousseau, D. L. and S. Han. 2002. Time-Resolved Resonance Raman Spectroscopy of Intermediates in Cytochrome Oxidase. Methods in Enzymology, 354, 351-368. https://doi.org/10.1016/S0076-6879(02)54028-3

Salie, M. J. and J. J. Thelen. 2016. Regulation and structure of the heteromeric acetylCoA carboxylase. Biochimica et Biophysica Acta, 1861, 1207-1213. https://doi.org/10.1016/j.bbalip.2016.04.004

Santos, M.M., R. Ruivo, A. Capitão, E. Fonseca and L.F.C. Castro. 2018. Identifying the gaps: Resources and perspectives on the use of nuclear receptor based-assays to improve hazard assessment of emerging contaminants. Journal of Hazardous Materials, 358, 508-511.https://doi.org/10.1016/j.jhazmat.2018.04.076

Santos, M. M., R. Ruivo, M. Lopes-marques, T. Torres, C.B.D L. Santos, L.F.C. Castro and T. Neuparth. 2016. Statins : An undesirable class of aquatic contaminants? Aquatic Toxicology, 174, 1-9. https://doi.org/10.1016/j.aquatox.2016.02.001

Sazanov, L.A. and J.B. Jackson. 1994. Proton-translocating transhydrogenase and NADand NADP-linked isocitrate dehydrogenases operate in a substrate cycle which contributes to fine regulation of the tricarboxylic acid cycle activity in mitochondria. FEBS Letters, 344, 109-116. https://doi.org/10.1016/0014-5793(94)00370-X

Schointuch, M.N., T.P. Gilliam, J.E. Stine, X. Han, C. Zhou, P.A. Gehrig, K. Kim and V.L. Bae-Jump. 2014. Simvastatin, an HMG-CoA reductase inhibitor, exhibits antimetastatic and anti-tumorigenic effects in endometrial cancer. Gynecologic Oncology, 134, 346-355. https://doi.org/10.1016/j.ygyno.2014.05.015

Schulz, J.G., J. Bösel, M. Stoeckel, D. Megow, U. Dirnagl and M. Endres. 2004. HMGCoA reductase inhibition causes neurite loss by interfering with geranylgeranylpyrophosphate synthesis. Journal of Neurochemistry, 89, 24-32. https://doi.org/10.1046/j.1471-4159.2003.02305.x 
Segner, H. 2009. Zebrafish (Danio rerio) as a model organism for investigating endocrine disruption. Comparative Biochemistry and Physiology Part C: Toxicology \& Pharmacology, 149, 187-195. https://doi.org/10.1016/j.cbpc.2008.10.099

Sehayek, E., E. Butbul, R. Avner, H. Levkovitz and S. Eisenberg. 1994. Enhanced cellular metabolism of very low density lipoprotein by simvastatin. A novel mechanism of action of HMG-CoA reductase inhibitors. Eur J Clin Invest, 24, 173-178. https://doi.org/10.1111/j.1365-2362.1994.tb00984.x

Seidler, N.W. 2013. Basic Biology of GAPDH. Advances in experimental medicine and biology, 985, 1-36. https://doi.org/10.1007/978-94-007-4716-6_1

Sirvent, P., O. Fabre, S. Bordenave, D. Hillaire-Buys, E. Raynaud De Mauverger, A. Lacampagne and J. Mercier. 2012. Muscle mitochondrial metabolism and calcium signaling impairment in patients treated with statins. Toxicology and Applied Pharmacology, 259, 263-268.https://doi.org/10.1016/J.TAAP.2012.01.008

Smolders, I., I. Smets, O. Maier, M. vandeVen, P. Steels and M. Ameloot. 2010. Simvastatin interferes with process outgrowth and branching of oligodendrocytes. Journal of Neuroscience Research, 88, 3361-3375.

https://doi.org/10.1002/jnr.22490

Soengas, J.L. and M. Aldegunde. 2002. Energy metabolism of fish brain. Comparative Biochemistry and Physiology - B Biochemistry and Molecular Biology, 131, 271296. https://doi.org/10.1016/S1096-4959(02)00022-2

Sousa, M.A.D. de. 2013. Analysis of pharmaceutical residues in wastewaters, surface and drinking waters - study of the removal efficiency through conventional and advanced treatment processes. Faculdade de Farmácia da Universidade do Porto.

Tete, S.V., H. Nyoni, B.B. Mamba and T.A.M. Msagati. 2019. Occurrence and spatial distribution of statins, fibrates and their metabolites in aquatic environments. Arabian Journal of Chemistry https://doi.org/10.1016/j.arabjc.2019.08.003

Thelen, K.M., K.M. Rentsch, U. Gutteck, M. Heverin, M. Olin, U. Andersson, A. von Eckardstein, I. Björkhem and D. Lütjohann. 2006. Brain Cholesterol Synthesis in Mice Is Affected by High Dose of Simvastatin but Not of Pravastatin, 316, 11461152. https://doi.org/10.1124/jpet.105.094136.due

Thorpe, J. L., M. Doitsidou, S. Ho, E. Raz and S.A. Farber. 2004. Germ Cell Migration in Zebrafish Is Dependent on HMGCoA Reductase Activity and Prenylation. 
Developmental Cell, 6, 295-302. https://doi.org/10.1016/S1534-5807(04)00032-2

Vance, J.E. 2012. Dysregulation of cholesterol balance in the brain: contribution to neurodegenerative diseases. Disease Models \& Mechanisms, 5, 746-755. https://doi.org/10.1242/dmm.010124

Vandenberg, L.N., T. Colborn, T.B. Hayes, J.J. Heindel, D.R. Jacobs, D.H. Lee, T. Shioda, A.M. Soto, F.S. vom Saal, W.V. Welshons, et al. 2012. Hormones and endocrine-disrupting chemicals: low-dose effects and nonmonotonic dose responses. Endocrine Reviews, 33, 378-455. https://doi.org/10.1210/er.2011-1050

Vergauwen, L., D. Benoot, R. Blust and D. Knapen. 2010. Long-term warm or cold acclimation elicits a specific transcriptional response and affects energy metabolism in zebrafish. Comparative Biochemistry and Physiology, Part A, 157, 149-157. https://doi.org/10.1016/j.cbpa.2010.06.160

Verlicchi, P., M. Al Aukidy and E. Zambello. 2012. Occurrence of pharmaceutical compounds in urban wastewater: Removal, mass load and environmental risk after a secondary treatment-A review. Science of the Total Environment, 429, 123-155. https://doi.org/10.1016/j.scitotenv.2012.04.028

Xiang, Z. and S.A. Reeves. 2009. Simvastatin induces cell death in a mouse cerebellar slice culture (CSC) model of developmental myelination. Experimental Neurology, 215, 41-47. https://doi.org/10.1016/j.expneurol.2008.09.010

Xiuli, G., G. Meiyu and D. Guanhua. 2005. Glucose Transporter 1, Distribution in the Brain and in Neural Disorders: Its Relationship With Transport of Neuroactive Drugs Through the Blood-Brain Barrier. Biochemical Genetics, 43, 175-187. https://doi.org/10.1007/s10528-005-1510-5

Zala, D., M. Hinckelmann, H. Yu, M. Menezes, S. Marco and F.P. Cordelie. 2013. Vesicular Glycolysis Provides On-Board Energy for Fast Axonal Transport. Cell, 152, 479-491. https://doi.org/10.1016/j.cell.2012.12.029 
Table 1. Sequence of primers and other parameters used for qRT-PCR (5'-3') gene expression in the brain of $D$. rerio

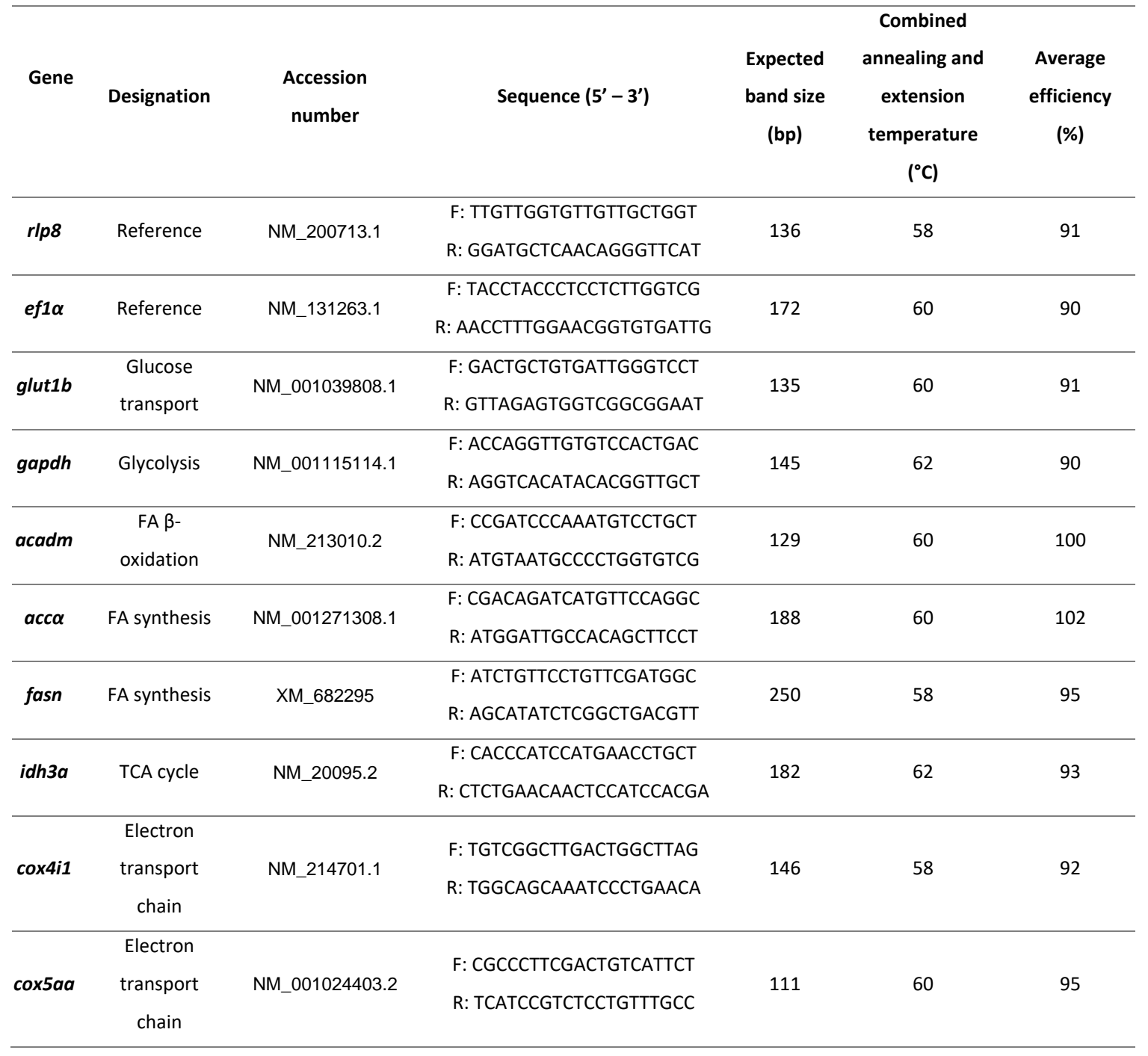



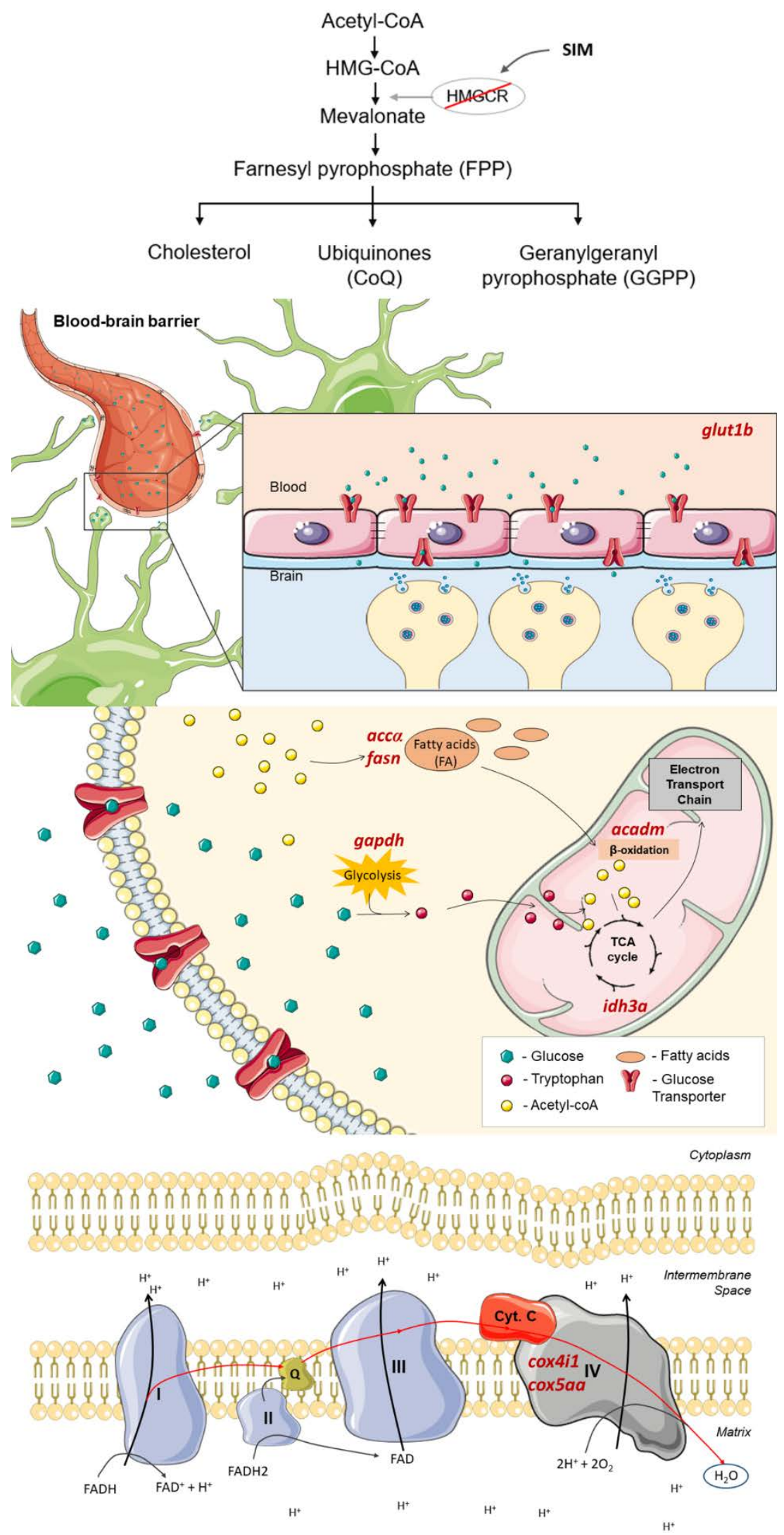

Figure 1. Interactions between brain energy metabolism and the mevalonate (MVA) pathway. Equal numbers indicate interactions between MVA pathway intermediates and key genes/enzymes used in the present study and involved in brain energy metabolism. 


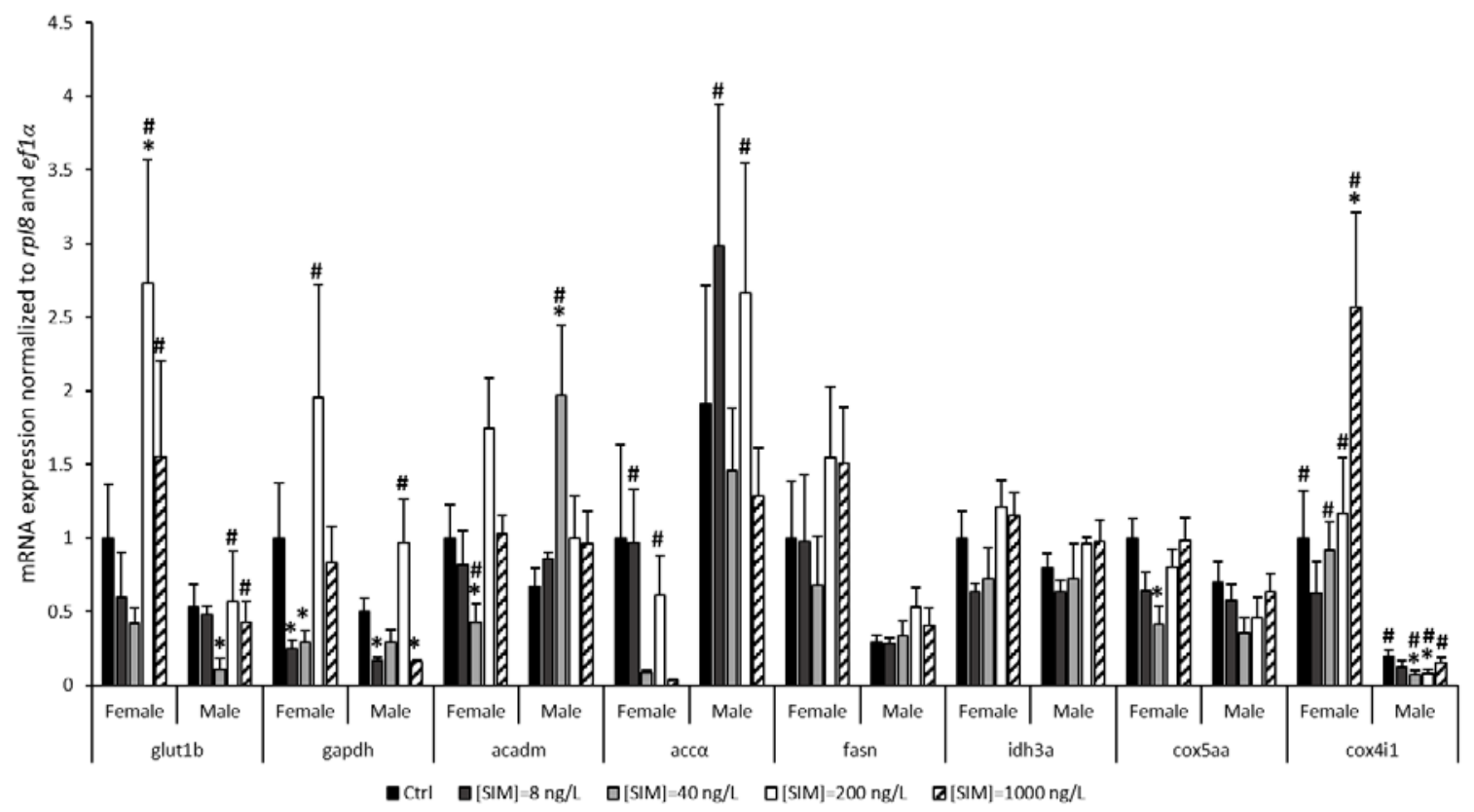

Figure 2. Relative mRNA expression of glut $1 \mathrm{~b}$, gapdh, acadm, acc $\alpha$, fasn, idh3a, cox4i1 and cox5aa in Danio rerio brain after 90 days of SIM exposure for males and females. Error bars indicate standard errors; asterisks $\left(^{*}\right)$ indicate significant differences from the control group and cardinals (\#) indicate significant differences between sexes $(\mathrm{p}<0.05)(\mathrm{n}=8$ per sex/treatment). The data was normalised to the female control (1 fold). 
A.

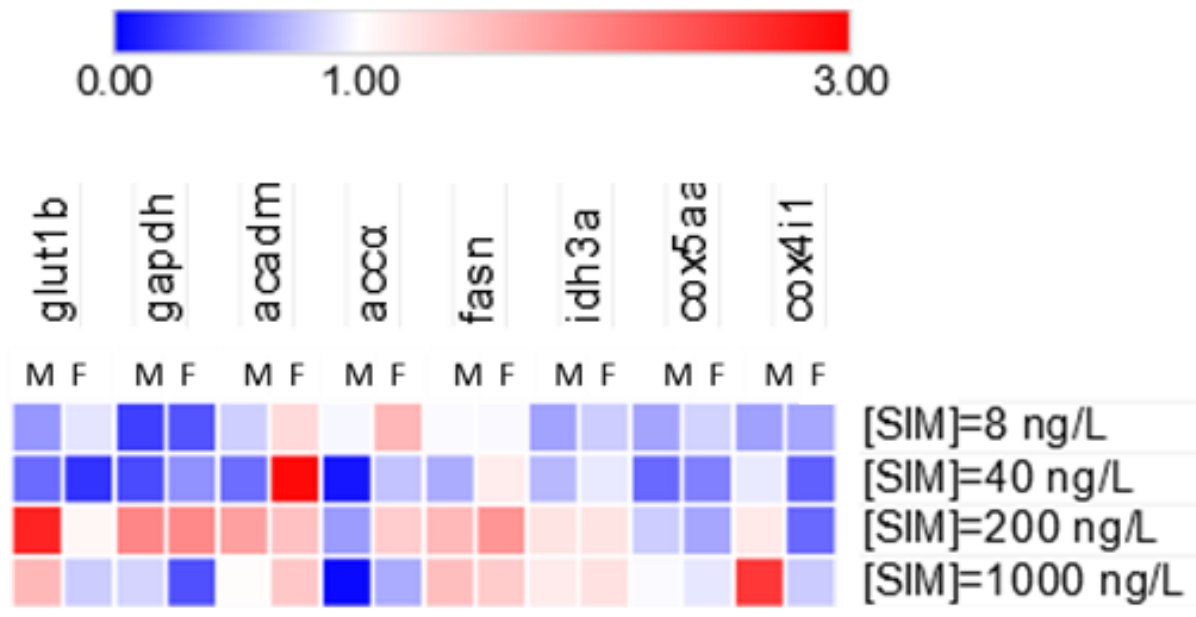

B.

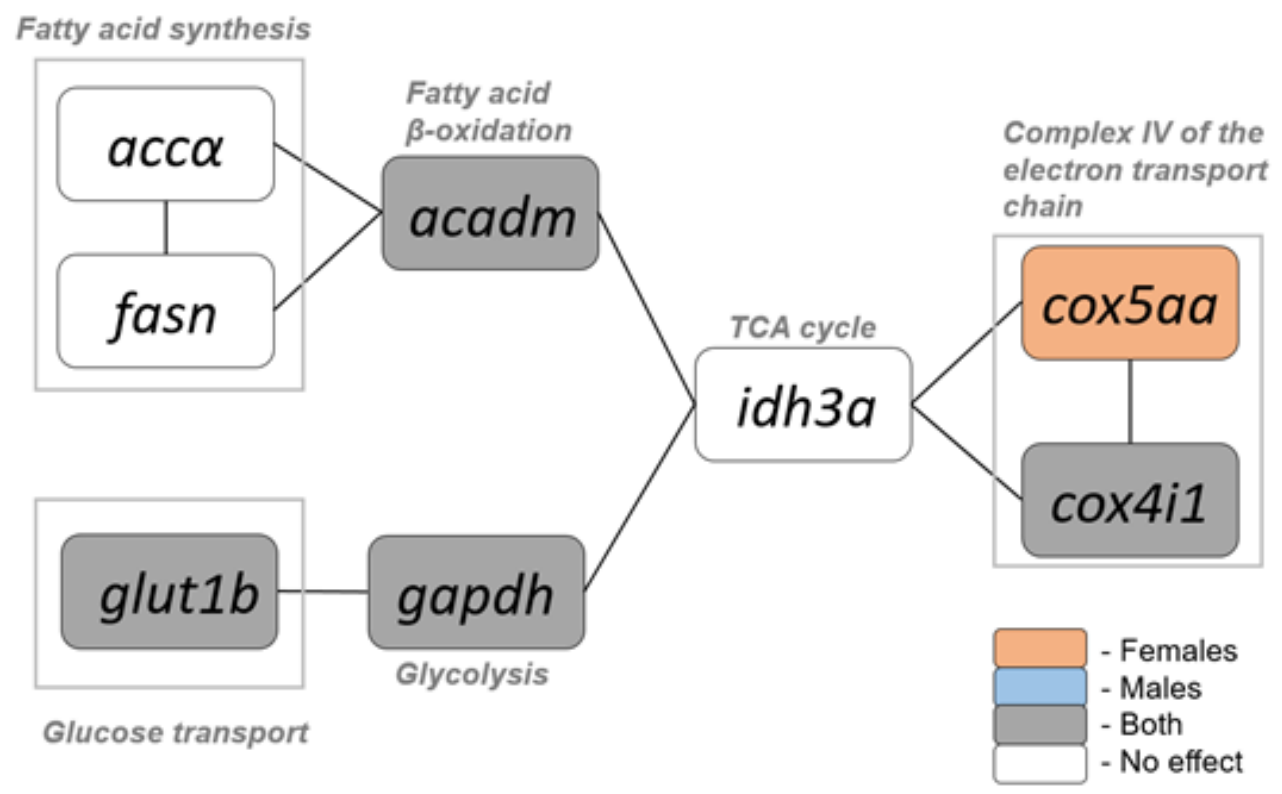

Figure 3. Summary of the gene expression in the brain of D. rerio following 90 days of exposure to SIM. A) Heatmap of the mRNA expression of glut1b, gapdh, acadm, acca, fasn, idh3a, cox4i1 and cox5aa presented as fold-differences from the control group (fold $=1$ ) in both males $(\mathrm{M})$ and females $(\mathrm{F}) . \mathrm{B})$ Altered gene expression $(\mathrm{p}<0.05)$, for at least one SIM concentration. 


\section{Figures captions:}

Figure 1. Interactions between brain energy metabolism and the mevalonate (MVA) pathway. Equal numbers indicate interactions between MVA pathway intermediates and key genes/enzymes used in the present study and involved in brain energy metabolism.

Figure 2. Relative mRNA expression of glut1b, gapdh, acadm, acc $\alpha$, fasn, idh3a, cox4i1 and cox5aa in Danio rerio brain after 90 days of SIM exposure for males and females. Error bars indicate standard errors; asterisks $(*)$ indicate significant differences from the control group and cardinals (\#) indicate significant differences between sexes $(\mathrm{p}<0.05)$ ( $\mathrm{n}=8$ per sex/treatment). The data was normalised to the female control (1 fold).

Figure 3. Summary of the gene expression in the brain of $D$. rerio following 90 days of exposure to SIM. A) Heatmap of the mRNA expression of glut1b, gapdh, acadm, acca, fasn, idh3a, cox4i1 and cox5aa presented as fold-differences from the control group (fold $=1)$ in both males $(\mathrm{M})$ and females $(\mathrm{F}) . \mathrm{B})$ Altered gene expression $(\mathrm{p}<0.05)$, for at least one SIM concentration. 